\title{
Fetal outcome of HIV positive pregnant women taking highly active antiretroviral therapy at Yaoundé Central Hospital: a cross sectional analytic study
}

\section{Fouedjio J. H. ${ }^{1,2 *}$, Loweh Limyuy Ntani $^{2}$, Fouelifack Ymélé Florent ${ }^{1,3}$, Mbu Robinson Enow ${ }^{1,3}$}

\author{
${ }^{1}$ Yaoundé Central Hospital, Cameroon \\ ${ }^{2}$ Department of Medicine and Biomedical Sciences, University of Yaoundé, Cameroon \\ ${ }^{3}$ Higher Institute of Health Sciences, Nkolndom-Yaoundé
}

Received: 27 August 2017

Accepted: 25 September 2017

\section{*Correspondence: \\ Dr. Fouedjio J. H., \\ E-mail: fouedjiojeanne@yahoo.fr}

Copyright: (C) the author(s), publisher and licensee Medip Academy. This is an open-access article distributed under the terms of the Creative Commons Attribution Non-Commercial License, which permits unrestricted non-commercial use, distribution, and reproduction in any medium, provided the original work is properly cited.

\begin{abstract}
Background: HIV infection in pregnant women is delicate both for the mother and her child. With the adoption of option B + treatment plan by Cameroon's ministry of public health, there has been a marked decrease in the vertical transmission of HIV from mothers to their babies. There is a dearth of evidence in sub-Saharan Africa, especially in Cameroon, on the effects of highly active antiretroviral therapy (HAART) on pregnancy and foetal outcomes with respect to the time from onset of treatment. We therefore carried out this study to determine the foetal outcome of women on HAART. We hypothesized that the foetal outcome is poorer for pregnant women starting HAART during pregnancy compared to those starting HAART prior to conception.

Methods: We carried out an analytic cross-sectional study which spanned from the $1^{\text {st }}$ February to $30^{\text {th }}$ April 2017 at the Yaoundé Central Maternity. We included consenting hospitalised HIV infected women who just terminated a pregnancy (abortion or delivery), and who started HAART at least four weeks before termination of pregnancy. Data was analysed using EPI info 7.2.1.0. SPSS version 20.0. Odds ratio (OR) was used to assess the degree of association that could exist between qualitative variables. The threshold of statistical significance was set at a p-value of 0.05 .

Results: A total of 121 participants were recruited in the present study. The mean age of the participants was $31.3 \pm 5.3$ years for those who started HAART before pregnancy and 29.4 \pm 5.5 years for those who started during pregnancy $(\mathrm{p}=0.07)$. The viral loads means for those who started taking HAART before pregnancy $34.6 \pm 21.5 \mathrm{cells} / \mathrm{mm}^{3} \mathrm{and}$ those who started during pregnancy $60 \pm 14$ cells $/ \mathrm{mm}^{3}(\mathrm{p}=0.01)$. Overall there were not any significant adverse fetal outcomes caused by taking HAART before or during pregnancy $(\mathrm{p}>0.05)$.

Conclusions: Despite the fact that the viral load was more elevated in women starting HAART prior pregnancy compared to those started during pregnancy, there was no significant adverse foetal outcome related to time of initiation of HAART treatment by pregnant HIV positive in Yaoundé central Maternity. We suggest that the implementing of the test and treat strategy will have a positive impact on the vertical transmission of HIV.
\end{abstract}

Keywords: Fetal outcome, HAART, HIV

\section{INTRODUCTION}

Since the publication of the first cases of HIV (Human Immunodeficiency Virus) infection in the United States in 1981, it has always been a major problem of public health and development, especially in sub-Saharan African where the vast majority of people living with HIV are in low- and middle-income countries. Sub- 
Saharan Africa is the most affected region, with an estimated 25.6 million people living with HIV in 2015. About $66 \%$ of new HIV infections in 2015 occurred in sub-Saharan Africa. ${ }^{1}$ According to the United Nation program on HIV/AIDS (UNAIDS), 36.7 million people were infected with HIV globally at the end of 2015, amongst which were 2.1 million newly infected cases. ${ }^{2}$ Out of these 37 million people as of June 2016, 18.2 million $(50 \%)$ people living with HIV had access to antiretroviral therapy. Meanwhile, $77 \%$ of pregnant women living with HIV had access to anti-retroviral medicines to prevent the transmission of HIV to their babies. ${ }^{3}$

Over the last decade, treatment for the Prevention of Mother to Child Transmission (PMTCT) of HIV has moved from AZT to the use of Highly Active Antiretroviral Therapy (HAART) - with global transmission rates dropping to $1-2 \% .{ }^{4}$ In Cameroon, the prevalence of HIV was estimated to be $4.3 \%$ in the general population and as per a progress report in 2015, Rapport de progres PTME N10, pregnant woman showed an HIV prevalence of $4.1 \% .^{5}$ Hence the need to sensitize and treat those who were infected which involved many other methods including the increase of the number of pregnant women taking HAART PMTCT. Since 2011 there has been a marked increase in treatment coverage globally, especially in sub-Saharan Africa. ${ }^{6}$ In a similar fashion, remarkable progress in treatment coverage for infected pregnant women has been registered from $6.9 \%$ to $36.5 \%$ in a bid to improve maternal and infant mortality. ${ }^{7}$

Results have been reported on the high risk of adverse pregnancy outcomes in HIV infected women treated with HAART. ${ }^{8,9}$ In a study conducted in Botswana, for example, HAART taken during pregnancy was closely related to preterm deliveries (PTD), but less so for gestational age (SGA) and still births (SB). ${ }^{8}$ Similar studies carried out in South Africa concluded that these women were exposed, together with their children, to adverse effects that were strongly related to the time of commencement of the ART. ${ }^{10}$

In Cameroon, the 2015 national directives for management of HIV recommend that the option $\mathrm{B}+$ should be used for the PMTCT. This option was adopted in August 2012 and recommends the systematic initiation of Antiretroviral Therapy (ART) for life among all pregnant or nursing HIV-positive women regardless of the clinical and immunologic stage. ${ }^{11}$ This then strongly goes to increase the population of people having access to ART and with most of them being women and pregnant women being the majority taking ART either for their babies' health or theirs least probably. ${ }^{12}$

In as much as the importance of taking HAART for HIV infected pregnant mothers is indisputable, it is very necessary and important to monitor their intake during pregnancy and its relationship with the aforementioned adverse outcomes. We therefore carried out this study with the hypothesis that the foetal outcome is poorer for pregnant women starting HAART during pregnancy compared to those starting HAART prior to conception. Our general objective was to determine the foetal outcome of women on HAART. The specific objectives were to describe the socio-demographic characteristics of pregnant HIV-positive women, to evaluate the history of HAART treatment of the women and to compare the foetal outcomes of the women who started taking HAART prior to conception and those who started during pregnancy.

\section{METHODS}

We carried out an analytic cross-sectional study. Participants for this study were recruited from the Central Hospital Maternity recorded as a referral center for antiretroviral treatment in Yaoundé located at Messa. It was founded alongside the hospital in 1933 with treatment of HIV/AIDS one of the main activities. The gynecological and obstetrical unit called the maternity comprises of 12 doctors (gynecologist and residents), nurses and medical students on internship. The service has 70 beds, 4 labour-rooms, a delivery room, 2 theatres, 4 consultation offices and a student hall for educational purposes. Preventive and curatives activities are carried out every day for pregnant and non-pregnant women. The service realizes about 300 deliveries per months included HIV pregnant women.

This study was carried out from December 2016 to May 2017, a period of 6 months.

The Target population was HIV-positive pregnant women. We included consented HIV infected women who were hospitalized and terminated pregnancy and who have taking HAART at least 4 weeks before termination of pregnancy. The sample size for the present study was calculated using the Lorenz formula. Thus, the minimum acceptable sample size for the study was 60 participants.

The ethical clearance was obtained from the Ethical Committee of the Faculty of Medicine and Biomedical Sciences to carry out this study. The data was collected through pre-established questionnaire.

The Women who were hospitalized and just terminated their pregnancy were met in the specified health facility and thoroughly informed on the study, its aims and confidentiality. Those who met our inclusion criteria and agreed to participate were then given a pre-established questionnaire. The participants were assisted throughout the filling of the questionnaire with the help of their antenatal hospital books. We divided our study population into two groups. The first group was made of women on HAART who started prior to pregnancy, women on HAART who started during the course of the pregnancy. The variables studied were: 
- the Socio-demographic status of the participants: age, level of education, occupation, civil status of the participant;

- history of antiretroviral treatment: duration of treatment was started, CD4 count, viral load;

- fetal outcome: first minute Apgar score, still birth, prematurity, birth weight, neonatal resuscitation, transferred to the neonatal unit.

The complete data was documented in data entry forms and visual checking for obvious errors and inconsistences in data was done. All data was then entered into EPI info version 7.2.1.0 and validated.

Data was then analysed using EPI info version 7.2.1.0 and SPSS version 20.0. Results were then presented as mean with standard deviation, minima and maxima for quantitative variables. For skewed distributions, we used the median and corresponding interquartile range to present results of quantitative variables.

For qualitative variable, the frequencies and proportions were calculated. We did a bivariate analysis to look for association between the delivery outcomes and taking
HAART. The associations between independent variable (moment of HAART commencement) and preterm delivery or low birth weight were examined using the chi-squared test, that is using the chi squared test for qualitative data and Student's t-test for quantitative variables. The degree of association was determined using the Odd's ratio with a confidence interval at $95 \%$. The level of statistical significance was set at a p-value $<0.05$.

\section{RESULTS}

\section{Sociodemographic characteristics of study population}

A total of 121 participants were included in this study. The ages of the participants ranged from 17 to 44 years with a mean age of $31.3 \pm 5.3$ years for women who started HAART before pregnancy and $29.4 \pm 5.5$ years for women who started HAART during pregnancy during pregnancy $(p=0.07)$. Among the different maternal occupations analysed with respect to those who started before and during pregnancy the mothers with liberal professions were statistically significant $(p=0.04)$ as seen in Table 1.

Table 1: Sociodemographic characteristics of study population.

\begin{tabular}{|c|c|c|c|c|}
\hline Variables & $\begin{array}{l}\text { Started HAART } \\
\text { before pregnancy } N=67 ; n(\%)\end{array}$ & $\begin{array}{l}\text { Started HAART during } \\
\text { pregnancy } \mathbf{N}=\mathbf{5 4} ; \mathbf{n}(\%)\end{array}$ & Total & P value \\
\hline Age & & & & 0.07 \\
\hline$\leq 20$ & $2(2.9)$ & $6(11.1)$ & $8(6.6)$ & \\
\hline $21-25$ & $10(14.9)$ & $6(11.1)$ & $16(13.2)$ & \\
\hline $26-30$ & $17(25.4)$ & $20(37)$ & $37(30.6)$ & \\
\hline $31-35$ & $18(26.9)$ & $16(29.6)$ & $34(28.1)$ & \\
\hline $36-40$ & $20(29.9)$ & $6(11.1)$ & $26(21.5)$ & \\
\hline \multicolumn{5}{|c|}{ Level of education } \\
\hline None & $0(0)$ & $0(0)$ & $0(0)$ & \\
\hline Primary & $0(0)$ & $0(0)$ & $0(0)$ & \\
\hline Secondary & $16(23.9)$ & $25(46.3)$ & $41(34)$ & 0.001 \\
\hline Tertiary & $51(76.1)$ & $29(53.7)$ & $80(66)$ & 1 \\
\hline Marital status & & & & 0.06 \\
\hline Couple & $43(64.2)$ & $29(53.7)$ & $72(59.5)$ & \\
\hline Single & $24(35.8)$ & $25(46.3)$ & $49(40.5)$ & \\
\hline \multicolumn{5}{|l|}{ Occupation } \\
\hline Student & $7(10.5)$ & $7(13)$ & $14(11.6)$ & 0.16 \\
\hline Unemployed & $5(7.5)$ & $5(9.2)$ & $10(8.3)$ & 0.21 \\
\hline Liberal & $32(47.8)$ & $33(61.1)$ & $65(53.6)$ & 0.04 \\
\hline Non-liberal & $23(34.2)$ & $9(16.7)$ & $32(25.5)$ & 1 \\
\hline
\end{tabular}

\section{Participants history of HAART treatment}

Length of time spent by participant on treatment.

There was a statistically significant difference between the time with which those who started taking treatment before pregnancy spent on treatment and that of those who started during pregnancy with $\mathrm{p}$ value $<0.01$ (Table 2).

\section{Viral load and CD4 count}

The viral load was statistically significant different in the two groups with a p value of 0.01 (Table 3). 
Table 2: Duration on treatment.

\begin{tabular}{|c|c|c|c|c|c|}
\hline Variable & & $\begin{array}{l}\text { Started HAART } \\
\text { before pregnancy } \\
\text { n }(\%)\end{array}$ & $\begin{array}{l}\text { Started HAART } \\
\text { during pregnancy } \\
\text { n (\%) }\end{array}$ & Total & P value \\
\hline \multirow{7}{*}{$\begin{array}{l}\text { Mean time on treatment } \pm \text { SD } \\
\text { (months) } \\
\text { Duration on treatment } \\
\text { (months) }\end{array}$} & & $45.5 \pm 29.3$ & $6.5 \pm 6.1$ & & $<0.01 *$ \\
\hline & $\leq 25$ & $25(37.3)$ & $53(98.1)$ & $78(64.5)$ & \\
\hline & $26-51$ & $23(34.3)$ & $1(1.9)$ & $24(19.8)$ & \\
\hline & $52-77$ & $11(16.4)$ & $0(0)$ & $11(9.0)$ & \\
\hline & $78-103$ & $4(6.0)$ & $0(0)$ & $4(3.3)$ & \\
\hline & $104-129$ & $3(4.5)$ & $0(0)$ & $3(2.5)$ & \\
\hline & $130-159$ & $1(1.5)$ & $0(0)$ & $1(0.8)$ & \\
\hline
\end{tabular}

Table 3: Viral load and CD4 count.

\begin{tabular}{|llll|} 
Variable & $\begin{array}{l}\text { Started HAART } \\
\text { before pregnancy }\end{array}$ & $\begin{array}{l}\text { Started HAART } \\
\text { during pregnancy }\end{array}$ & P value \\
\hline Viral Load, Mean \pm SD & $34.6 \pm 21.5$ & $60 \pm 14$ & $0.01^{*}$ \\
CD4 count, Mean \pm SD & $622.1 \pm 247.5$ & $572 \pm 200$ & 0.72 \\
\hline
\end{tabular}

Table 4: Foetal outcomes.

\begin{tabular}{|lllll|}
\hline Variable & $\begin{array}{l}\text { Started HAART before } \\
\text { pregnancy, } \\
\text { n }(\%)\end{array}$ & $\begin{array}{l}\text { Started HAART } \\
\text { during pregnancy, } \\
\text { n(\%) }\end{array}$ & OR (95\% CI) & P value \\
\hline Neonatal asphyxia & $2(3.2)$ & $1(2.2)$ & $0.7(0.05-7.7)$ & 1.00 \\
\hline LBW & $10(15.6)$ & $6(12.5)$ & $1.2(0.4-3.8)$ & 0.79 \\
\hline Admitted in neonatology & $26(35.9)$ & $21(31.1)$ & $0.5(0.2-1.1)$ & 0.12 \\
\hline Neonatal resuscitation & $19(22.2)$ & $12(35.4)$ & $0.5(0.2-1.1)$ & 0.14 \\
\hline Prematurity & $13(22.4)$ & $6(10.1)$ & $0.6(0.2-1.6)$ & 0.44 \\
\hline Fresh Still births & $1(1.6)$ & $2(4.2)$ & $2.7(0.2-31.1)$ & 0.58 \\
\hline
\end{tabular}

\section{Participants foetal outcomes}

Among all the foetal outcomes analysed, none of these factors were found to be statistically significant (Table 4).

\section{DISCUSSION}

\section{Sociodemographic characteristics}

Most of participants were between the ages of 26 to 30 years. This finding is similar to the 2011 report of the Demographic Health Survey (DHS). ${ }^{13}$

In the present study, most of the women were liberal with no stable salaries, majority of whom started HAART during pregnancy. A greater number of women who started HAART during pregnancy were found in the liberal group can be explained by postulating that given that these women do not have a stable source of income, few of them get to respect their hospital rendezvous or frequent hospital milieus for check-up as per the findings of Bogart et al. in a study in south Africa who reported that finances are a great barrier to patients coming to hospitals except they really need to. Consequently, their statuses are discovered late thereby commencing their
ART late or during pregnancy. ${ }^{14}$ In the health domain, general education is a fundamental tool in the decoding of messages of communication for the change of behaviour or for mobilisation against certain diseases, with education and health having a proportional relationship as per the findings of Ross and Mirowsky. ${ }^{15}$ In the present study the majority of women had at least tertiary education and higher $(66 \%)$ with a greater percentage starting HAART before pregnancy $(63.8 \%)$ followed by women having at most secondary education $(34 \%)$ in which those who started HAART during pregnancy $(46.3 \%)$ had a higher prevalence than those that started before pregnancy $(25.9 \%)$. This then confirms the findings of Baker et al. who said that formal schooling adds significant value to innate ability in the form of higher-order cognitive skills crucial to decisions about health. ${ }^{16}$

Nonetheless the present findings of more women in the tertiary group was contradicted by the findings of $\mathrm{Ngemu}$ et al. In that said that most of the pregnant women on HAART where having at most a secondary level of education Kenya. ${ }^{17}$ This difference might be explained by the general improvement of education in all the sectors in developing countries. ${ }^{18}$ 


\section{History of HAART treatment}

As expected, participants who started HAART pregnancy had a lower viral count and a higher CD4+ counts, compared to their counterparts who started HAART during pregnancy. This finding corroborated to the findings of some authors who discover that early therapy brings immediate intervention against a virus known to be causing immune damage and provides the potential for preservation of HIV-specific CD4 cells and lowers the viral load to reduce infectivity. ${ }^{19,20}$ Obviously, women who started HAART before pregnancy had a significantly longer time on treatment compared to those who started HAART during pregnancy. This could explain could explain our findings to a certain degree.

\section{Fetal outcomes of participants}

Most studies confirm that delivery outcomes are as a result of starting HAART before pregnancy and are specifically at times in relation to protease inhibitor based ART. ${ }^{21,22}$ With this in mind we tried to find out the adverse reactions of the ART but we didn't have any women on protease inhibitors. This can might be explained by the increase of the use of the combination therapy tenofovir-lamivudine-efavirenz and also the presence of too many side effects of Protease inhibitors as reported by the findings of Walli et al. ${ }^{23}$ Hence this has kept many medical personnel prescribing this particular treatment regimen.

In Cameroon in the cross-sectional analytic study, in our analysis adverse foetal outcomes where more common in women who started HAART before pregnancy than those who stated during pregnancy. This is in line with Machado and Alemu's studies who found that preconception HAART was associated with an increased risk for premature delivery and low birth weight and also in the UK and Ireland, Townsend et al findings suggested the prematurity rate ( $<37$ weeks gestation) was higher in women on highly active antiretroviral therapy (HAART) than in women on mono/dual therapy. ${ }^{4,24}$ Even after adjustments, delivery at $<35$ weeks was even more strongly associated with HAART. In the present study there was no significant difference between the delivery outcomes of those who started HAART before and during pregnancy as the findings of Nlend et al showed but the odds ratio show adverse foetal outcomes liable to happen to those who started during pregnancy than those who started HAART before. ${ }^{25}$ Except for LBW and still births where the opposite is true. Hence HAART didn't show to have significant outcome effect with respect to the time of initiation of treatment.

Overall, the rate of LBW or prematurity was quite lower than previous reports in Africa. In Ethiopia where the rate of LBW was recorded above $30 \%$ in women under HAART during pregnancy, reaching almost $50 \%$ in those on ART prior to pregnancy added to a rate of PTD above $20 \% .{ }^{26}$ In Botswana, HAART started prior to conception or during pregnancy was significantly associated to PTD, in almost $10 \%$ rate ingestion of PI, other worse outcomes including stillbirths. ${ }^{8}$ Out of Africa, worrying levels of both PTB and LBW reaching $20 \%$ or above have been posted from India, Germany and Austria though some reports have focused on the side effects of HAART prior to conception on birth outcomes. ${ }^{4,21,27}$

Finally, the present findings are matching the observational results earlier reported in the cohort study conducted in Drug Resource Enhancement Against AIDS and Malnutrition (DREAM) centers covering many settings in Africa which are favoring the wide use of HAART to improve the maternal immunologic states resulting to a better delivery outcomes of their children. ${ }^{28}$ Altogether, the favorable outcome of this observational study can be attributed to the immune state of the mothers which is sparsely compromised as well as the restricted use of protease inhibitors incriminated in some studies. ${ }^{29}$ Though limited, the results of this analysis defend the harmlessness of HAART prior to pregnancy versus during pregnancy as previously reported and therefore is supportive to the recent recommendations to generalize combined antiretroviral therapy during pregnancy by using a preferable first line of ART free of PI in low resources settings. ${ }^{30}$

This study was conducted in health facility, the Maternity; therefore, the results cannot be generalized because they arise from hospital based data

\section{CONCLUSION}

Despite the fact that the viral load was more elevated in women starting HAART prior pregnancy compared to those started during pregnancy, there was no significant adverse foetal outcome related to time of initiation of HAART treatment by pregnant HIV positive in Yaoundé Central Maternity. We suggest that the implementing of the test and treat strategy will have a positive impact on the vertical transmission of HIV.

\section{ACKNOWLEDGMENTS}

Authors would like to thank Yaoundé Central Hospital who gave us permission to carry out the study at their institution.

Funding: No funding sources Conflict of interest: None declared

Ethical approval: The study was approved by the Institutional Ethics Committee

\section{REFERENCES}

1. Global Statistics. The Global HIV/AIDS Epidemic. Available at https://www.aids.gov/hiv-aidsbasics/hiv-aids-101/global-statistics/ cited 2016 Dec 22. 
2. UNAIDS. Fact sheet November 2016. Available at http://www.unaids.org/en/resources/fact-sheet cited 2016 Dec 22

3. Global AIDS update 2016. Global AIDS update. Available at http://www.unaids.org/sites/default/files/media_asset /global-AIDS-update-2016_en.pdf cited 2016 Dec 2.

4. Machado ES, Hofer CB, Costa TT, Nogueira SA, Oliveira RH, Abreu TF, et al. Pregnancy outcome in HIV-1-infected women receiving combination antiretroviral therapy prior versus after conception. Sex Transm Infect. 2009;85(2):82-7.

5. Mesmey E, Liliane E, Anastasie M, de Dieu MJ, Arlette M, Emilienne N, et al. Towards elimination of mother-to-child transmission of HIV on the horizon 2015. Progress report PMTCT-Cameroon. 2015. Available at http://www.cnls.cm/docs/Rapport_de_Progr\%C3\%A 8s_PTME_2014_final.pdf

6. Tonwe-Gold B, Ekouevi DK, Viho I, Amani-Bosse C, Toure S, Coffie PA, et al. Antiretroviral treatment and prevention of peripartum and postnatal hiv transmission in West Africa: evaluation of a twotiered approach. PLoS Med. 2007;4(8).

7. Global report on AIDS statistics, information and facts about HIV AIDS, Global Events, USA, Europe, Middle East, Asia Pacific. Available at http://hivaids-std.conferenceseries.com/events-list/globalreport-on-aids-statistics-information-and-facts-abouthiv-aids [cited 2016 Dec 2].

8. Chen JY, Ribaudo HJ, Souda S, Parekh N, Ogwu A, Lockman S, et al. Highly active antiretroviral therapy and adverse birth outcomes among HIV-Infected Women in Botswana. J Infect Dis. 2012;206(11):1695-705.

9. van der Merwe K, Hoffman R, Black V, Chersich M, Coovadia A, Rees H. Birth outcomes in South African women receiving highly active antiretroviral therapy: a retrospective observational study. J Int AIDS Soc. 2011;14:42.

10. Hirnschall G, Harries AD, Easterbrook PJ, Doherty MC, Ball A. The next generation of the World Health Organization's global antiretroviral guidance. J Int AIDS Soc. 2013;16(1).

11. WHO. Antiretroviral therapy (ART) coverage among all age groups. WHO. Available at http://www.who.int/gho/hiv/epidemic_response/ART _text/en/ [cited 2016 Dec 2].

12. Njim T, Atashili J, Mbu R, Choukem SP. Low birth weight in a sub-urban area of Cameroon: an analysis of the clinical cut-off, incidence, predictors and complications. BMC Pregnancy Childbirth. 2015;15:288.

13. Bogart LM, Chetty S, Giddy J, Sypek A, Sticklor L, Walensky RP, et al. Barriers to care among people living with HIV in South Africa: contrasts between patient and healthcare provider perspectives. AIDS Care. 2013;25(7):843-53.
14. Ross CE, Mirowsky J. The Interaction of personal and parental education on health. Soc Sci Med. 2011;72(4):591-9.

15. Baker DP, Leon J, Greenaway EG, Collins J, Movit M. The Education Effect on Population Health: a reassessment. Popul Dev Rev. 2011;37(2):307-32.

16. Ngemu EK, Khayeka-Wandabwa C, Kweka EJ, Choge JK, Anino E, Oyoo-Okoth E. Effectiveness of option B highly active antiretroviral therapy (HAART) prevention of mother-to-child transmission (PMTCT) in pregnant HIV women. BMC Res Notes. 2014;7:52.

17. Glenwe $P$, Karthik. Improving school education outcomes in developing countries: Evidence, knowledge gaps, and policy implications. Available at

http://www.bsg.ox.ac.uk/sites/www.bsg.ox.ac.uk/file s/documents/RISE_WP-

001_Glewwe_Muralidharan.pdf cited on 2017 May 31

18. Erb P, Battegay M, Zimmerli W, Rickenbach M, Egger M. Effect of antiretroviral therapy on viral load, CD4 cell count, and progression to acquired immunodeficiency syndrome in a community human immunodeficiency virus-infected cohort. Swiss HIV Cohort Study. Arch Intern Med. 2000;160(8):113440.

19. Phillips AN, Staszewski S, Weber R, Kirk O, Francioli P, Miller V, et al. HIV viral load response to antiretroviral therapy according to the baseline CD4 cell count and viral load. JAMA. 2001;286(20):2560-7.

20. Franke MF, Spiegelman D, Ezeamama A, Aboud S, Msamanga GI, Mehta S, et al. Malaria Parasitemia and CD4 $\mathrm{T}$ cell count, viral load, and adverse hiv outcomes among HIV-infected pregnant women in Tanzania. Am J Trop Med Hyg. 2010;82(4):556-62.

21. Ekouevi DK, Coffie PA, Becquet R, Tonwe-Gold B, Horo A, Thiebaut R, et al. Antiretroviral therapy in pregnant women with advanced HIV disease and pregnancy outcomes in Abidjan, Côte d'Ivoire. AIDS Lond Engl. 2008;22(14):1815-20.

22. Walli R, Herfort O, Michl GM, Demant T, Jäger H, Dieterle C, et al. Treatment with protease inhibitors associated with peripheral insulin resistance and impaired oral glucose tolerance in HIV-1-infected patients. AIDS Lond Engl. 1998;12(15):F167-73.

23. Kebede B, Andargie G, Gebeyehu A. Birth outcome and correlates of low birth weight and preterm delivery among infants born to HIV-infected women in public hospitals of Northwest Ethiopia. Health (NY). 2013;05(07):25.

24. Chiu IM, Yaniv A, Dahlberg JE, Gazit A, Skuntz SF, Tronick SR, et al. Nucleotide sequence evidence for relationship of AIDS retrovirus to lentiviruses. Nature. 1985;317(6035):366-8.

25. Wiley: Sampling Techniques, $3^{\text {rd }}$ Edition - William G. Cochran. Available at http://eu.wiley.com/WileyCDA/WileyTitle/productC d-047116240X.html cited on 2016 Dec 1. 
26. Grosch-Woerner I, Puch K, Maier RF, Niehues T, Notheis G, Patel D, et al. Increased rate of prematurity associated with antenatal antiretroviral therapy in a German/Austrian cohort of HIV-1infected women. HIV Med. 2008;9(1):6-13.

27. Marazzi MC, Palombi L, Nielsen-Saines K, Haswell J, Zimba I, Magid NA, et al. Extended antenatal use of triple antiretroviral therapy for prevention of mother-to-child transmission of HIV-1 correlates with favorable pregnancy outcomes. AIDS Lond Engl. 2011;25(13):1611-8.

28. Cotter AM, Garcia AG, Duthely ML, Luke B, O'Sullivan MJ. Is antiretroviral therapy during pregnancy associated with an increased risk of preterm delivery, low birth weight, or stillbirth? J Infect Dis. 2006;193(9):1195-201.
29. Ahmed S, Kim MH, Abrams EJ. Risks and benefits of lifelong antiretroviral treatment for pregnant and breastfeeding women: a review of the evidence for the Option B+ approach. Curr Opin HIV AIDS. 2013;8(5):474-89.

30. Watts DH, Mofenson LM. Antiretrovirals in pregnancy: a note of caution. J Infect Dis. 2012;206(11):1639.

Cite this article as: Fouedjio JH, Ntani LL, Florent FY, Enow MR. Fetal outcome of HIV positive pregnant women taking highly active antiretroviral therapy at Yaoundé Central Hospital: a cross sectional analytic study. Int J Reprod Contracept Obstet Gynecol 2017;6:4791-7. 